\title{
Establishment and characterization of human osteosarcoma cells resistant to pyropheophorbide- $\alpha$ methyl ester-mediated photodynamic therapy
}

\author{
YONG TAO ${ }^{1,3}$, YUNSHENG OU ${ }^{1}$, HANG YIN $^{1}$, YANYANG CHEN ${ }^{1}$, SHENXI ZHONG $^{1}$, YONGJIAN GAO ${ }^{1}$, \\ ZENGHUI ZHAO $^{1}$, BIN HE $^{1}$, QIU HUANG ${ }^{2}$ and QIANXING DENG ${ }^{3}$ \\ ${ }^{1}$ Department of Orthopedics, The First Affiliated Hospital of Chongqing Medical University, Yuzhong, Chongqing 400016; \\ ${ }^{2}$ Department of Orthopedics, People's Hosipital of Leshan, Leshan, Sichuan 614000; \\ ${ }^{3}$ Department of Orthopedics, People's Hospital of Fengdu, Fengdu, Chongqing 408200, P.R. China
}

Received May 17, 2017; Accepted September 8, 2017

DOI: 10.3892/ijo.2017.4136

\begin{abstract}
The present study was performed to establish and characterize new human osteosarcoma cell lines resistant to pyropheophorbide- $\alpha$ methyl ester-mediated photodynamic therapy (MPPa-PDT). MPPa-PDT-resistant cells are isolated from the human osteosarcoma MG63 and HOS cell lines and two resistant populations were finally acquired, including MG63/PDT and HOS/PDT. Cell Counting Kit-8 (CCK-8) assay was used to determine the MPPa-PDT, cisplatin (CDDP) resistance and proliferation of MG63, MG63/PDT, HOS and HOS/PDT cells. The intracellular ROS were analyzed using DCFH-DA staining. The colony formation, invasion and migration of parental and resistant cells were compared. FCM was employed to examine the cell cycle distribution, the apoptosis rate and the proportion of $\mathrm{CD}_{133^{+}}$cells. The fluorescence intensity of intracellular MPPa was observed by fluorescence microscopy and quantified using microplate reader. The protein levels were assessed by western blotting (WB). Compared with two parental cells, MG63/PDT and HOS/PDT were 1.67- and 1.61-fold resistant to MPPa-PDT, respectively, and also exhibited the resistance to CDDP. FCM assays confirmed that both MG63/PDT and HOS/PDT cells treated with MPPa-PDT displayed a significantly lower apoptosis rate in comparison with their corresponding parental cells. The expression of apoptosis-related proteins (i.e. cleaved-caspase 3 and cleaved-PARP), intracellular ROS and the antioxidant proteins (HO-1 and SOD1) in MG63/PDT and HOS/PDT cells was also lower than that in parental cells. Both MG63/PDT and HOS/PDT cells exhibited changes in
\end{abstract}

Correspondence to: Dr Yunsheng Ou, Department of Orthopedics, The First Affiliated Hospital of Chongqing Medical University, 1 You Yi Road, Yuanjiagang, Yuzhong, Chongqing 400016, P.R. China

E-mail: ouyunsheng2001@163.com

Key words: human osteosarcoma cell, PDT resistance, pyropheophorbide- $\alpha$ methyl ester proliferation, photosensitizer absorption, colony formation, invasion, migration and the cell cycle distribution as compared to MG63 and HOS cells, respectively. Compared to MG63 and HOS cells, both resistant cell lines had a higher expression of CD133, survivin, Bcl-xL, Bcl-2, MRP1, MDR1 and ABCG2, but a lower expression of Bax. The present study successfully established two resistant human osteosarcoma cell lines which are valuable to explore the resistance-related mechanisms and the approaches to overcome resistance.

\section{Introduction}

Osteosarcoma is well known as the most common primary malignant bone tumor in clinic. It is strongly invasive and has poor prognosis, and mainly occurs in children and adolescents (1-3). Photodynamic therapy (PDT), a new promising approach for tumor therapy, is featured by excellent selectivity, less side reactions, and visible light of specific wavelength to excite photosensitizer enriched in tumor tissue, which can subsequently result in reactive oxygen, mainly singlet oxygen to cause tumor cell death $(4,5)$. In addition, PDT has already been used in the treatment of skin and esophageal cancer, and other tumors (6-8). MPPa, a second generation photosensitizer derived from chlorophyll, has many advantages including stability, single component, rapid absorption and metabolism and strong photosensitivity (9). It has been reported that MPPa-PDT can kill tumor cells such as nasopharyngeal carcinoma, prostate and breast cancer cells (10-12).

However, photodynamic therapy may lead to the resistance of tumor cells (13). Numerous mechanisms are reported to mediate the resistance of tumor cells (14). Furthermore, the surviving tumor cells play an important role in the recurrence and deterioration of tumor, and result in poor prognosis $(15,16)$. It has been reported that the increased expression of HO1, SOD1 and other antioxidant proteins can protect tumor cells from ROS damage (17). ATP-binding cassette (ABC) transporters (e.g. ABCG2, MRP1 and MDR1) were found to mediate tumor cell resistance, and alleviate cell damage through pumping out intracellular toxins (18). Furthermore, the overexpression of anti-apoptotic protein $\mathrm{P}$-survivin was responsible for 
chemoresistance and radio-resistance of tumor cells (19). The Bcl-2 protein family can regulate the permeability of mitochondrial membrane, and its expression can decrease the sensitivity of tumor cells to antitumor therapy (20). The present study aimed to establish human osteosarcoma cell lines resistant to MPPa-PDT. The resistant cell lines can also be employed to investigate the resistance mechanism of human osteosarcoma cells to MPPa-PDT and explore the approach to overcome MPPa-PDT resistance.

\section{Materials and methods}

Reagents and instruments. MPPa and 2'7'-dichlorofluorescin diacetate (DCFH-DA) were purchased from Sigma-Aldrich (St. Louis, MO, USA). BCA and trypsin were purchased from Beyotime Biotech (Shanghai, China). Cell viability and cytotoxicity test kits [Cell Counting Kit-8 (CCK-8)] were obtained from Dojindo Molecular Technologies (Kumamoto, Japan). Extracellular matrix gel was obtained from BD Biosciences (Franklin Lakes, NJ, USA). Annexin V-propidium iodide (PI) double-staining test kit was purchased from KeyGen Biotech (Nanjing, China). LED equipment was purchased from Chongqing Jingyu Laser Technology Co. Ltd. (Chongqing, China).

Antibodies. Primary antibodies were: $\beta$-actin $(1: 1,000)$, cleaved caspase-3 $(1: 1,000)$, SOD1 $(1: 1,000)$, cleaved PARP $(1: 1,000)$, $\operatorname{Bcl}-2$ (1:1,000), Bcl-xL (1:1,000), Bax (1:1,000), CD133 (1:1,000), MDR1 (1:500), MRP1 (1:500) and P-survivin (1:1,000; all from Cell Signaling Technology,Inc. Danvers, MA,USA), HO1 (1:500; Proteintech Group, Inc., Wuhan, China) and CD133-APC (1:20; BD Biosciences). Secondary antibodies were: HRP monoclonal antibody anti-IgG of mouse and HRP monoclonal antibody anti-IgG of rabbit (Cell Signaling Technology, Inc.).

Cell line and culture. MG63 and HOS cells were obtained from the Chinese Academy of Sciences (Shanghai, China), and cultured in Dulbecco's modified Eagle's medium (DMEM) supplemented with 10\% fetal bovine serum (FBS) (both from HyClone, Beijing, China), $100 \mu \mathrm{g} / \mathrm{ml}$ penicillin and $100 \mu \mathrm{g} / \mathrm{ml}$ streptomycin (Beyotime Biotech) at $37^{\circ} \mathrm{C}$ in a humidified atmosphere containing $5 \% \mathrm{CO}_{2}$.

Resistance induction to MPPa-PDT. MG63 and HOS cells were cultured in the dark and incubated with different MPPa concentrations (Fig. 1A and B) for $20 \mathrm{~h}$, and then washed twice with phosphate-buffered saline (PBS). The culture medium was replaced, and the cells were exposed to red light $(630 \mathrm{~nm}$, $40 \mathrm{~mW} / \mathrm{cm}^{2}$ ) in the continuous output mode. Treatment conditions that caused survival rates of $40-60 \%$ were chosen. The dead cells were wiped off and the surviving cells were cultured in fresh complete medium continuously for $24 \mathrm{~h}$. Twenty hours later, the cells were harvested and replaced. They were subjected to a new PDT with intermittently increased doses of MPPa. The final populations were obtained following a total of 10 cycles of PDT, and they were MG63/PDT and HOS/PDT.

MPPa-PDT sensitivity assay. CCK-8 was used to investigate the sensitivity of cell lines MG63, MG63/PDT, HOS and HOS/PDT to MPPa-PDT. Cells were plated in 96-well plates at a density of $5 \times 10^{3}$ cells/well with 3 duplications. After a 24-h incubation, the culture medium was replaced with the fresh medium containing different concentrations of MPPa $(0$, $0.25,0.5,0.75$ and $1.0 \mu \mathrm{M}$ for MG63 and MG63/PDT; $0,0.1$, $0.15,0.2$ and $0.25 \mu \mathrm{M}$ for HOS and HOS/PDT cells). The cells were then cultured for $20 \mathrm{~h}$. The culture medium was replaced, and the cells were exposed to red light $\left(630 \mathrm{~nm}, 40 \mathrm{~mW} / \mathrm{cm}^{2}\right)$. Twenty-four hours later, the cells were incubated for $1 \mathrm{~h}$ with $10 \mu$ l CCK-8 in each well. A microplate reader was employed to detect the absorption values of CCK-8 at $450 \mathrm{~nm}$. The cell viability was calculated according to the following formulation:

Cell viability $(\%)=$ Average $\mathrm{OD}$ in experiment group/ average OD in control group x $100 \%$

Resistance indices (RIs) $=\mathrm{IC}_{50}$ values for resistant cells/ $\mathrm{IC}_{50}$ values for parental cells

Based on the results of the cell viability test, we chose an MPPa concentration of $0.45 \mu \mathrm{M}$ for MG63 and MG63/PDT cells and $0.15 \mu \mathrm{M}$ for HOS and HOS/PDT cells with a light energy density of $4.8 \mathrm{~J} / \mathrm{cm}^{2}$ as the treatment conditions.

Detection of apoptosis rate by Annexin V-PI double staining and FCM. Cells were seeded in 6-well plates at a density of $1 \times 10^{5}$ cells/well. All cells were harvested after corresponding treatments, and assessed by FCM after Annexin V-PI double staining (KeyGen Biotech).

Cell proliferation assay by $C C K-8$. Cells were seeded in 96-well plates at a density of $5 \times 10^{3}$ cells/well. When all cells attached, the cell viability was determined using the CCK- 8 assay at $0,12,24$ and $48 \mathrm{~h}$.

Cell cycle analysis by FCM. Cells were seeded in 6-well plates at a density of $1 \times 10^{5}$ cells/well. After incubation for $\sim 36 \mathrm{~h}$, when fusion was up to $\sim 60-70 \%$, all groups were collected at the same time and washed twice, and fixed by suspending in $70 \%$ ethanol at $4^{\circ} \mathrm{C}$ for $24 \mathrm{~h}$, and then subjected to FCM.

Assessment of intracellular ROS level by DCFH-DA staining. Cells were inoculated in 6- and 24-well plates, at a density of $1 \times 10^{5}$ and $5 \times 10^{4}$ cells/well, respectively. Following the corresponding treatments, the cells were further incubated for $2 \mathrm{~h}$. Then, DCFH-DA $(10 \mu \mathrm{M})$ was added at $37^{\circ} \mathrm{C}$ for $20 \mathrm{~min}$. Finally, cells in 24-well plates were observed by fluorescence microscope (FM) after being washed 3 times, and the cells in 6-well plates were determined by FCM after being trypsinized and collected.

Assessment of CD133 by FCM. Cells were seeded in 6-well plates at a density of $1 \times 10^{5}$ cells/well. All cells were trypsinized, centrifuged and resuspended in PBS. CD133-APC (1:20) was added to corresponding groups and incubated in the dark for $10 \mathrm{~min}$ at $4^{\circ} \mathrm{C}$. After being washed, the cells were resuspended in PBS and analyzed by FCM.

Measurement of intracellular MPPa. Cells were inoculated in 6- and 96-well plates at a density of $1 \times 10^{5}$ and $5 \times 10^{3}$ cells/well, 

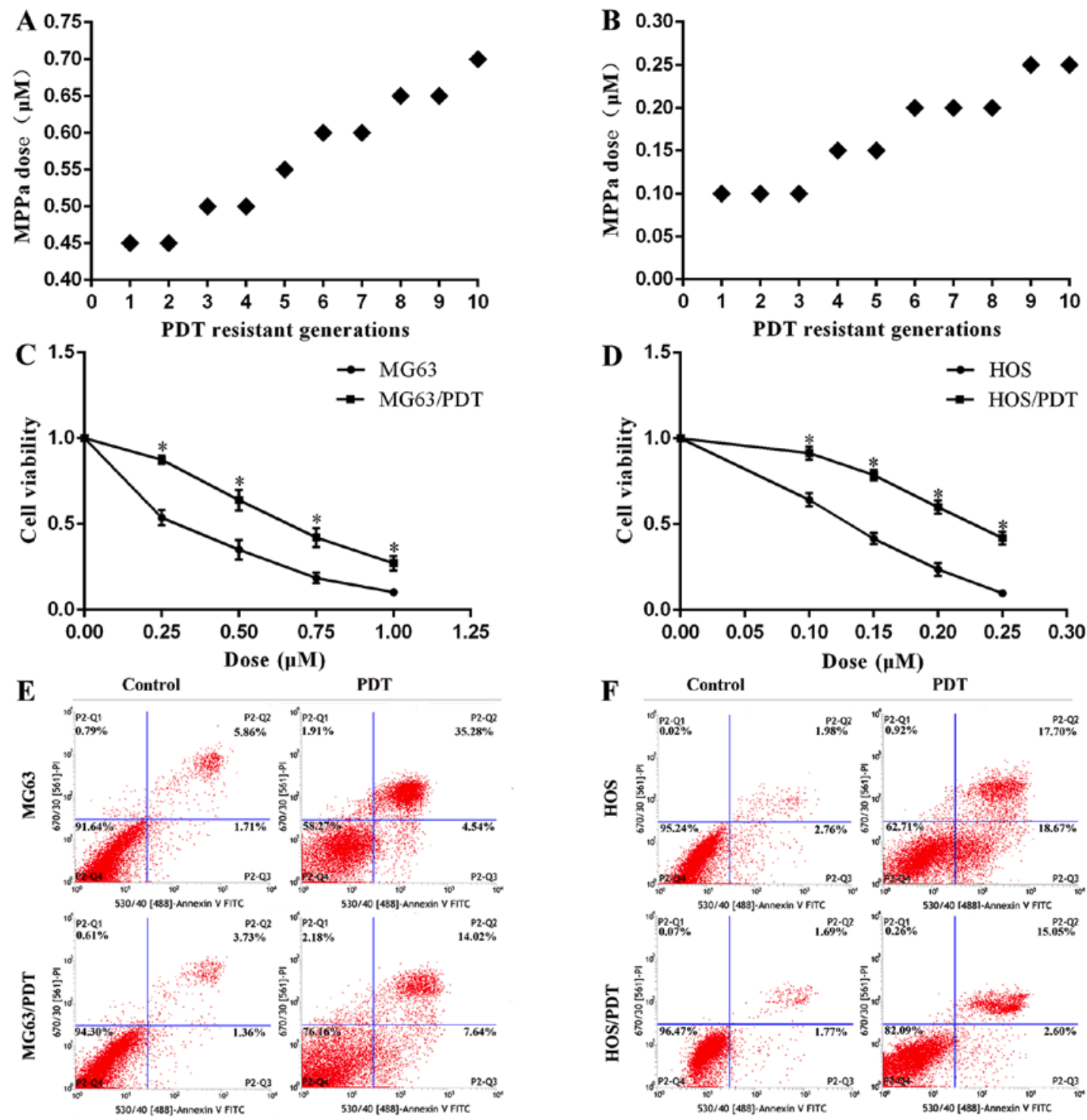

Figure 1. Establishment of the resistant cell lines. (A and B) Parental cell lines MG63 (left) and HOS (right) were subjected to 10 cycles of PDT with increasing doses of MPPa. (C and D) Cell viability was determined using CCK-8 after PDT at different concentrations of MPPa for 24 h. The cell viability of MG63/PDT and HOS/PDT were both higher than that of MG63 and HOS cells, respectively $(\mathrm{P}<0.05)$. (E and F) Apoptosis was assessed employing Annexin V-FITC/PI double staining followed by FCM. Apoptotic rates of MG63/PDT and HOS/PDT were markedly lower than that of their corresponding parental cells (P<0.001), after MPPa-PDT treatment for $12 \mathrm{~h}$. The results indicated that the new human osteosarcoma cell lines MG63/PDT and HOS/PDT resistant to MPPa-PDT were successfully established; ${ }^{*} \mathrm{P}<0.05$.

respectively. After attachment, the cells were incubated with different MPPa concentrations $(2,4$ and $8 \mu \mathrm{M})$ for $20 \mathrm{~h}$. Then, an inverted FM was used to observe the fluorescence of cells with $4 \mu \mathrm{M} \mathrm{MPPa}$ in 6-well plates, and a microplate reader was adopted to examine the fluorescence value of cells in 96-well plates $(\lambda \operatorname{exc} 525 \mathrm{~nm} ; \lambda$ em $680 \mathrm{~nm})$.

Colony formation assay. MG63 and MG63/PDT were seeded into 6-well plates at a density of 200 cells/well. HOS and HOS/PDT were seeded in 6-well plates at a density of 500 cells/well. The culture medium was replaced every 3 days. Two weeks later, colonies were fixed with polyformaldehyde (4\%) for $20 \mathrm{~min}$ and visualized by crystal violet solution.

Invasion and migration assays. The ECM $(1: 8,100 \mu \mathrm{l})$ was added to the top chamber and placed in an incubator for $2 \mathrm{~h}$. When the ECM was dried, 4x10 ${ }^{4}$ MG63 and MG63/PDT or
$8 \times 10^{4} \mathrm{HOS}$ and HOS/PDT cells in serum-free medium were added to the top chamber. In the lower chamber, complete medium was added. After incubation at $37^{\circ} \mathrm{C}$ in $5 \% \mathrm{CO}_{2}$ for $48 \mathrm{~h}$, the cells on the upper surface of the membrane were removed using a cotton swab. The cells on the lower surface of the membrane were fixed with polyformaldehyde (4\%) for $15 \mathrm{~min}$ and stained by crystal violet solution $(0.1 \%)$. Cells were observed by inverted phase contrast microscope. Five randomized fields at a magnification of $\mathrm{x} 40$ were selected. For the migration assay, a protocol similar to the invasive assay was performed, but without the ECM layer in the chamber, and the cells added as well as the incubation time was half of that in invasion assay, respectively.

Western blot analysis. Cells were rinsed with PBS and lysed by RIPA buffer containing a phosphatase and protease inhibitor cocktail. Protein concentration was assessed by 
A
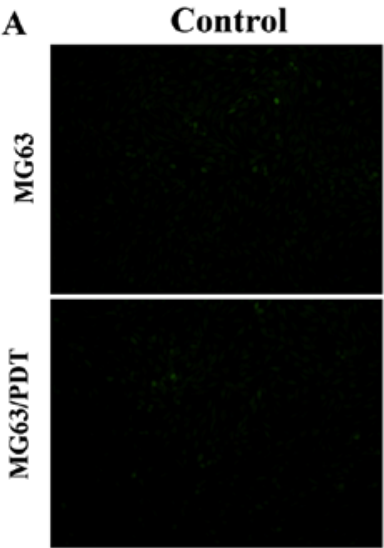

C
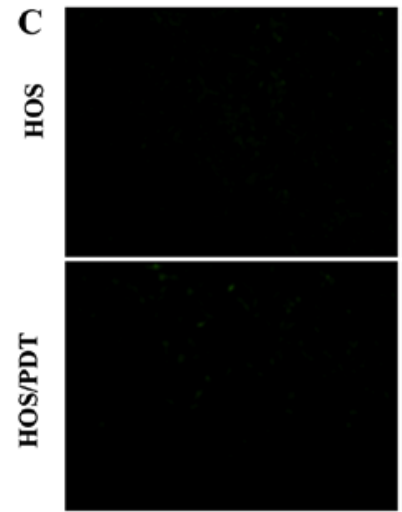

$\mathbf{E}$

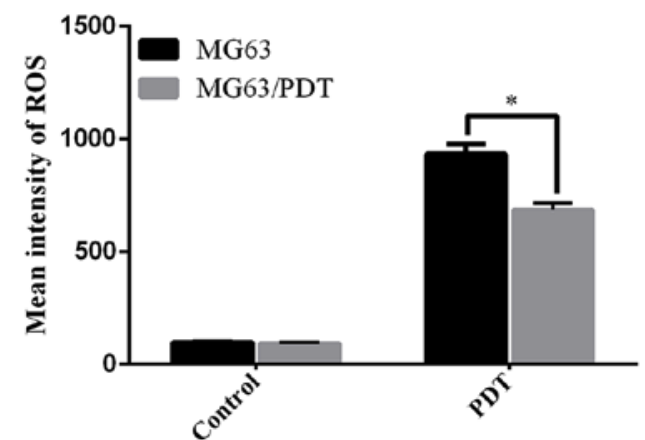

B
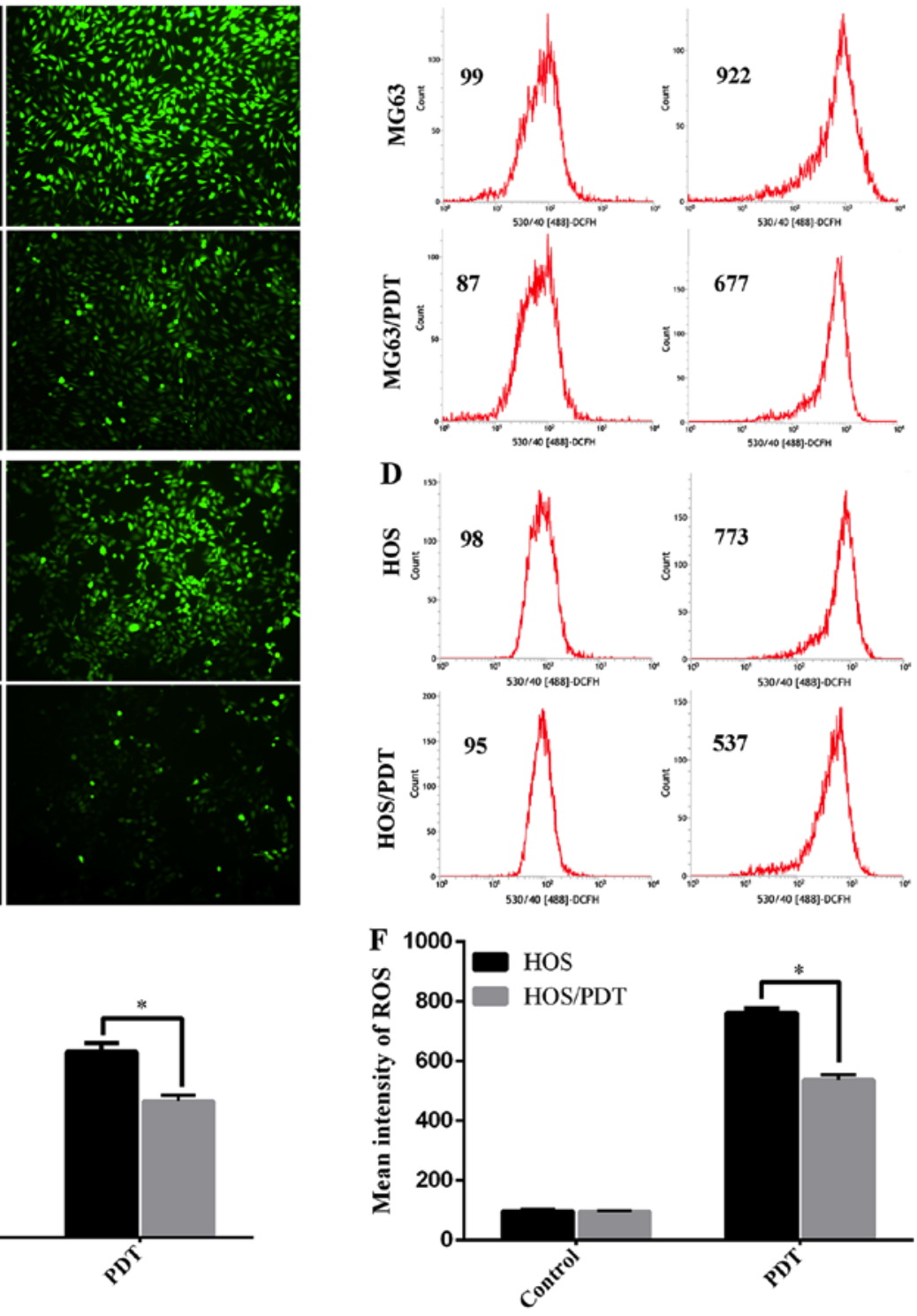

Figure 2. Cellular ROS in different cell types was examined using DCFH-DA (10 $\mu \mathrm{M})$ followed by FCM and inverted FM. (A and B) MG63 and MG63/PDT cells were treated with MPPa $(0.45 \mu \mathrm{M})$ for $20 \mathrm{~h}$, and then irradiated with light $\left(4.8 \mathrm{~J} / \mathrm{cm}^{2}\right)$. At $2 \mathrm{~h}$ after irradiation, the ROS level was observed by inverted FM and detected by FCM. (C and D) The ROS levels of HOS and HOS/PDT cells, undergoing the same treatment of MG63 and MG63/PDT cells except for MPPa $(0.15 \mu \mathrm{M})$, were assessed by the same methods as those for MG63 and MG63/PDT cells (A and C, magnification, x100). (E) The FCM status for MG63 and MG63/PDT cells from 3 independent experiments displayed in bar format. (F) The FCM data for HOS and HOS/PDT from 3 independent experiments displayed in bar format. The results revealed that the ROS level of MG63/PDT and HOS/PDT was significantly lower than that of parental MG63 and HOS cells, induced by MPPa-PDT; ${ }^{*} \mathrm{P}<0.05$.

BCA. Protein samples $(40 \mu \mathrm{g})$ were electrophoresed and blotted on polyvinylidene fluoride membranes, which were blocked in Tris-buffered saline containing Tween-20 and 5\% non-fat milk for $1 \mathrm{~h}$ at room temperature, and incubated with the corresponding primary antibodies overnight at $4^{\circ} \mathrm{C}$. After being rinsed, the membranes were subjected to the horseradish peroxidase-conjugated secondary antibody for $1 \mathrm{~h}$ and developed by electrochemiluminescence. Quantity One software was used to detect the gray values of some western bands. The relative expression of target proteins was displayed using the ratio of target protein $/ \beta$-actin. Three independent experiments were performed.

Statistical analysis. Data are expressed as the mean \pm SD and analyzed by SPSS (SPSS, Inc., Chicago, IL, USA). Differences between groups were determined using the one-way or two-way ANOVA test for intergroup and independent-sample t-test for two groups. At $\mathrm{P}<0.05$, the difference was considered significant.

\section{Results}

Establishment of the resistant cell lines. Parental cells, MG63 and HOS cells, were treated by PDT with increased concentration of MPPa for 10 cycles (Fig. 1A and B). The 10th generation of resistant cells obtained were named MG63/PDT and HOS/PDT, respectively. We employed MG63, HOS and MG63/PDT, HOS/PDT as experimental objects for the following studies. In order to verify the tolerance of resistant cells compared with their corresponding parental cells, the 

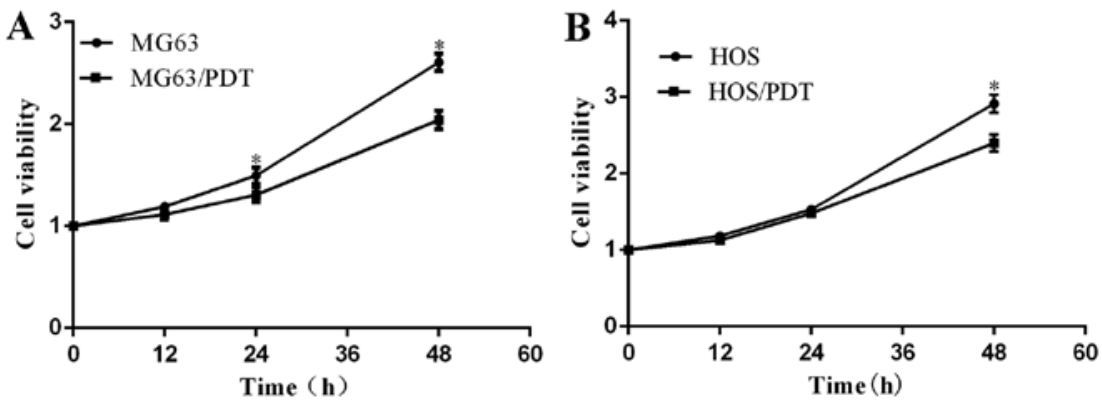

Figure 3. Cell proliferation of MG63, MG63/PDT, HOS and HOS/PDT cells. Cell viability was evaluated by CCK-8 at 0, 12,24 and 48 h, respectively; ${ }^{\mathrm{P}}<0.05$.

A
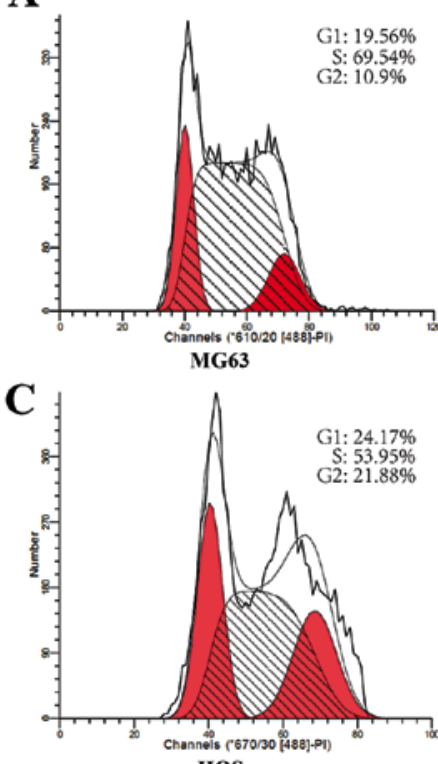

HOS
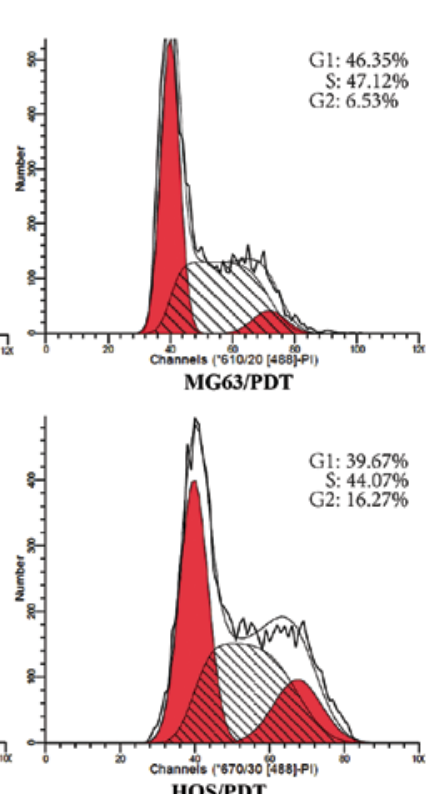
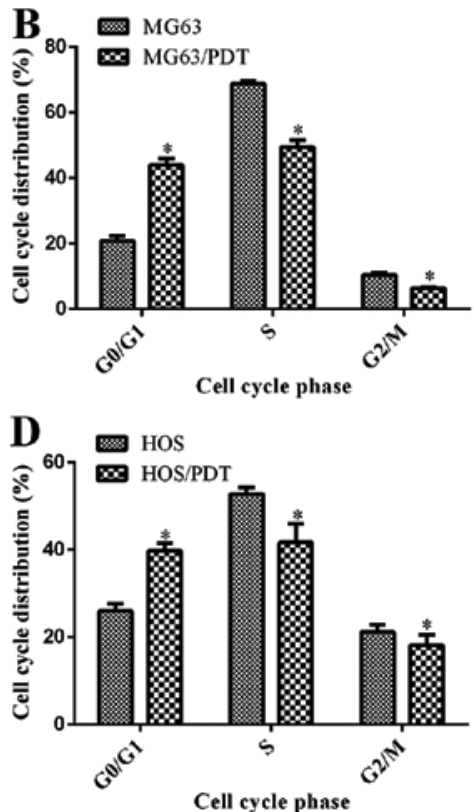

Figure 4. Cell cycle distribution of MG63, MG63/PDT, HOS and HOS/PDT cells tested by FCM. (A) MG63 and MG63/PDT, (C) HOS and HOS/PDT, as well as (B) FCM data for MG63 and MG63/PDT are shown in bar format. (D) FCM data for HOS and HOS/PDT exhibited in bar format. The proportion of MG63/PDT and HOS/PDT cells in the G2/M and S phases were significantly increased compared with the EC109 cells with a concomitant decrease in the G0/G1 phase. Similar results were observed between HOS and HOS/PDT cells; ${ }^{*} \mathrm{P}<0.05$.

cell viability and apoptosis rate were assessed after PDT. A CCK-8 assay demonstrated that the concentration at 50\% inhibition $\left(\mathrm{IC}_{50}\right)$ for MG63/PDT $(0.704 \pm 0.016 \mu \mathrm{M})$ was 1.67 -fold more resistant than that for MG63 $(0.421 \pm 0.028 \mu \mathrm{M} ; \mathrm{P}<0.001)$, and the concentration at $50 \%$ inhibition $\left(\mathrm{IC}_{50}\right)$ for HOS/PDT $(0.226 \pm 0.008 \mu \mathrm{M})$ was 1.61 -fold higher as compared to that for HOS $(0.140 \pm 0.004 \mu \mathrm{M})(\mathrm{P}<0.001$; Fig. $1 \mathrm{C}$ and $\mathrm{D})$. FCM indicated that the apoptosis rate of MG63/PDT (20.04 $\pm 2.16 \%)$ was markedly lower than that of MG63 (40.58 $2.34 \%)(\mathrm{P}<0.001$; Fig. 1E), when they were subjected to PDT with $0.45 \mu \mathrm{M} \mathrm{MPPa}$.

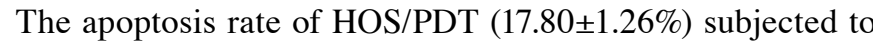
PDT with $0.15 \mu \mathrm{M}$ MPPa was also significantly lower than that of $\operatorname{HOS}(37.22 \pm 0.81 \%)(\mathrm{P}<0.001$; Fig. $1 \mathrm{~F})$.

Measurement of intracellular ROS by FCM and FM. FCM and FM demonstrated that there was no significant difference of intracellular ROS levels between MG63 and MG63/PDT cells without PDT treatment $(\mathrm{P}=0.267)$. However, the ROS level in MG63 cells was markedly higher than that in MG63/PDT after PDT treatment ( $\mathrm{P}=0.001)$ (Fig. 2A, B and E). Similar results were observed between HOS and HOS/PDT cells (Fig. 2C, D and F).
Cell proliferation test. After $12 \mathrm{~h}$ of culture, the MG63/PDT cells began to grow slower compared with the MG63 cells and the difference of growth speed was significant after $24 \mathrm{~h}$ $(\mathrm{P}=0.037$; Fig. 3A). However, HOS/PDT began to grow slower than the parental HOS cells after $24 \mathrm{~h}$, and the difference of growth speed was significant after $48 \mathrm{~h}$ ( $\mathrm{P}=0.005$; Fig. 3B). The proliferation curves of two types of resistant cells were more flat compared with that of the relatively primitive cells.

Examination of cell cycle distribution by FCM. FCM revealed that the proportion of cells in the G0/G1, S and G2/M phase were $19.56,69.54$ and $10.9 \%$ for MG63; 46.35, 47.12 and $6.53 \%$ for MG63/PDT (Fig. 4A); 24.17, 53.95 and 21.88\% for HOS; and 39.67, 44.07 and $16.27 \%$ for HOS/PDT (Fig. 4C), respectively. The MG63/PDT and HOS/PDT cells exhibited shorter $\mathrm{S}$ and $\mathrm{G} 2 / \mathrm{M}$ phases with a concomitantly longer G0/G1 phase in cycle distribution than their comparative cells $(\mathrm{P}<0.05$; Fig. 4B and D).

Invasion assay. Transwell assays with a layer of Matrigel on the top inserts were employed to examine the invasive capability. 


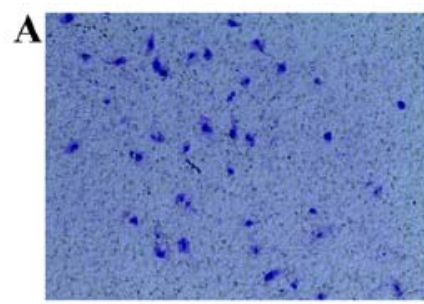

MG63

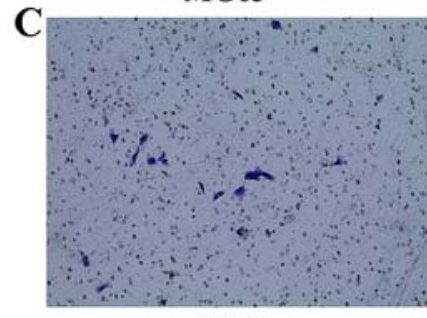

HOS

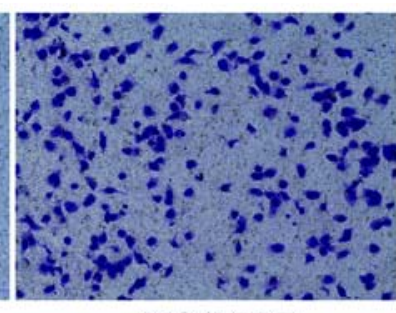

MG63/PDT

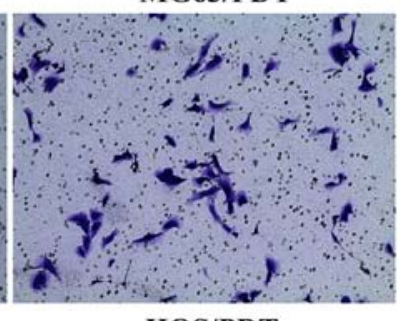

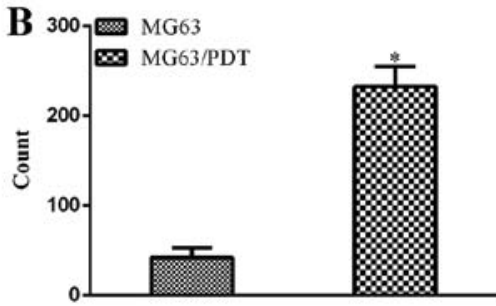

$\mathbf{D}_{150} \mathrm{mos}$

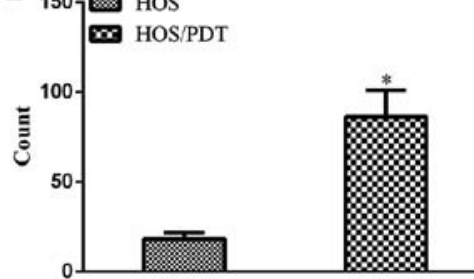

Figure 5. Invasive capability of (A) MG63, MG63/PDT and (C) HOS, HOS/PDT cells. (B and D) MG63/PDT and HOS/PDT cells were more invasive compared to parental MG63 and HOS cells; ${ }^{2} \mathrm{P}<0.05$. (A and C, magnification, $\mathrm{x} 40$ ).

A

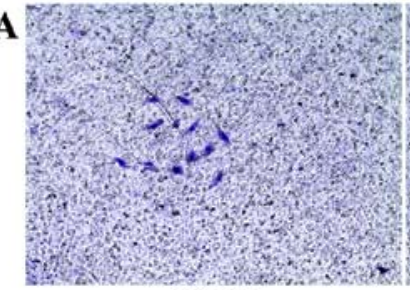

MG63

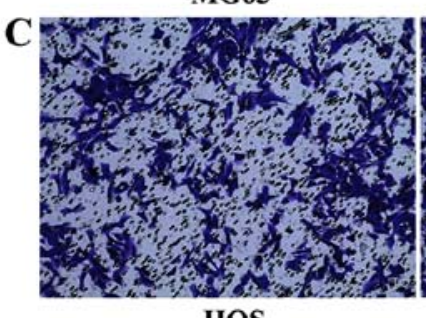

HOS

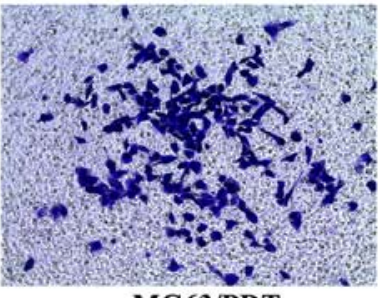

MG63/PDT

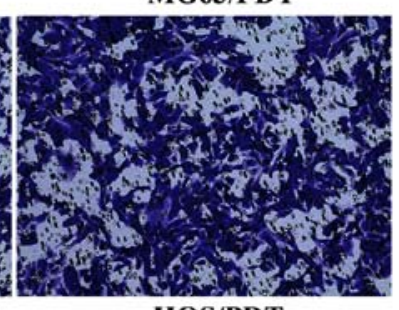

HOS/PDT
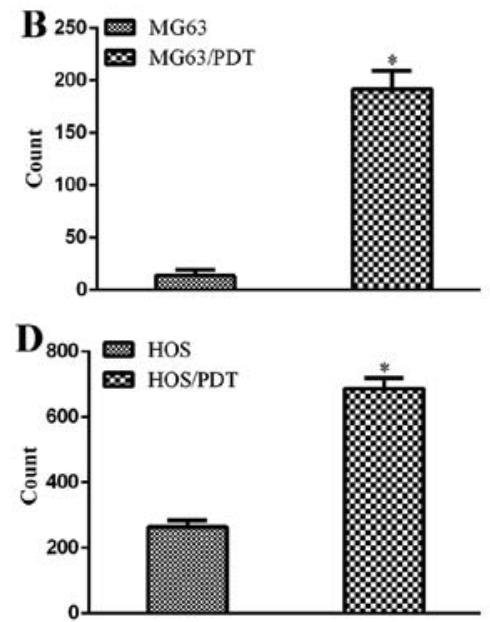

Figure 6. Migration capability of (A) MG63, MG63/PDT and (C) HOS, HOS/PDT cells. (B and D) The migration capability of the MG63/PDT and HOS/PDT cells was increased compared to parental MG63 and HOS cells, respectively; ${ }^{\mathrm{P}}<0.05$. (A and C, magnification, $\mathrm{x} 40$ ).

The results revealed that the number of cells penetrated both the Matrigel and membrane was $232 \pm 22.7$ for MG63/PDT cells, $42 \pm 11$ for MG63 cells (Fig. 5A and B), $86.33 \pm 14.64$ for HOS/PDT cells and 18.33 \pm 3.51 for HOS cells (Fig. 5C and D), demonstrating that MG63/PDT and HOS/PDT had better ability of invasiveness compared with their corresponding parental cells $(\mathrm{P}<0.05)$.

Migration assay. Transwell assay was performed to detect migration ability. The results indicated that the number of cells penetrating the membrane was $195 \pm 12.12$ for MG63/PDT cells, $13.67 \pm 5.68$ for MG63 cells (Fig. 6A and B), $687.33 \pm 31.72$ for HOS/PDT cells and $263.67 \pm 20.84$ for HOS cells (Fig. 6C and D), revealing that the migration ability of MG63/PDT and HOS/PDT cells were increased compared with parental MG63 and HOS cells, respectively $(\mathrm{P}<0.05)$.

Colony formation assay. Both MG63/PDT and HOS/PDT cells had more potential in forming colonies. The number of
MG63/PDT cell colonies (36.3 \pm 5.0$)$ was significantly higher compared to MG63 cells (21.3 $\pm 5.7, \mathrm{P}=0.027$; Fig. $7 \mathrm{~A}$ and $\mathrm{B})$. The number of HOS/PDT cell colonies $(22.3 \pm 4.5)$ was also markedly higher than HOS cells $(6.3 \pm 1.5, \mathrm{P}=0.004$; Fig. 7C and D).

Determination of osteosarcoma stem marker CD133 by $F C M$. FCM revealed that the proportion of $\mathrm{CD} 133^{+}$cells in MG63/PDT, MG63, HOS/PDT and HOS cells was $11.49 \pm 0.71$, $0.43 \pm 0.09,5.76 \pm 0.52$ and $0.50 \pm 0.06 \%$, respectively. MG63/PDT and HOS/PDT exhibited more CD133 ${ }^{+}$cells than their corresponding original cells (Fig. 8; $\mathrm{P}<0.05$ ).

Measurement of intracellular MPPa. The fluorescence intensity of MPPa cells was observed by FM. The results revealed that the fluorescence intensity of MPPa in MG63 cells was stronger than that of MG63/PDT (Fig. 9A), and the fluorescence intensity of MPPa in HOS cells was stronger than that of HOS/PDT cells (Fig. 9C). Microplate reader was 

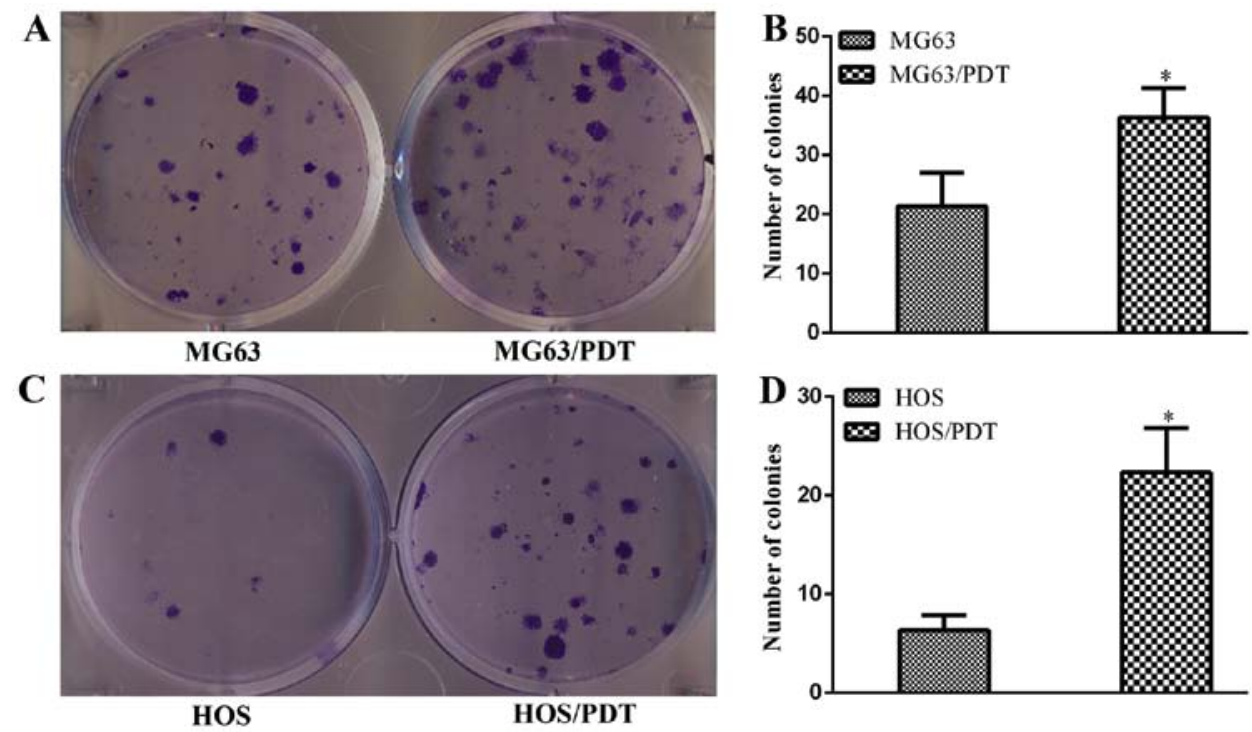

Figure 7. The colony formation of MG63, MG63/PDT, HOS and HOS/PDT cells. (A and C) MG63/PDT and HOS/PDT cells resulted in markedly more colonies than their corresponding parental cells. (B and D) The data are displayed in bar format. The MG63/PDT and HOS/PDT cells formed significantly more colonies compared to parental MG63 and HOS cells, respectively; ${ }^{*} \mathrm{P}<0.05$.
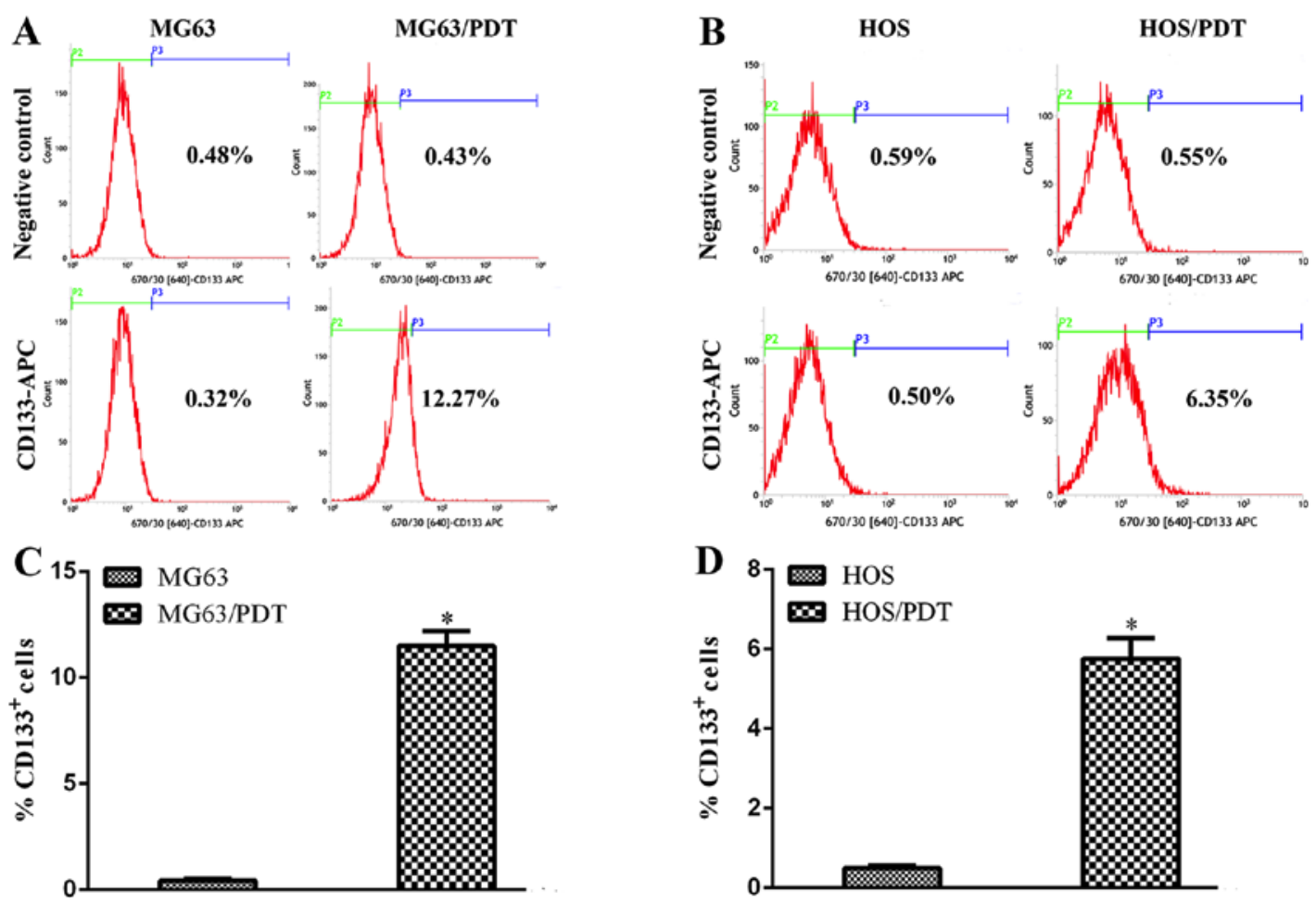

Figure 8. The proportion of cells expressing CD133. (A and B) The CD133 $3^{+}$proportion in all groups was determined by FCM, revealing that both MG63/PDT and HOS/PDT cell lines had more CD133+ cells than their parental MG63 and HOS cells, respectively. (C and D) FCM data for each group from 3 independent experiments exhibited in bar format. The results revealed that the proportion of CD133+ cells in MG63/PDT and HOS/PDT were significantly higher than that in their corresponding parental cells; ${ }^{*} \mathrm{P}<0.05$.

employed to quantify fluorescence intensity of MPPa in the cells, revealing that MPPa content in MG63 and HOS cells was significantly higher than that of MG63/PDT and HOS/PDT cells, respectively $(\mathrm{P}<0.05$; Fig. 9B and $\mathrm{D})$.

Cytotoxicity by CDDP. CCK-8 was adopted to assess the cytotoxicity of CDDP on PDT resistant and parental cells. Survival rates of MG63/PDT and HOS/PDT were significantly higher than those of the corresponding original MG63 and HOS cells $(\mathrm{P}<0.05$; Fig. 10).

Western blot assays. WB was used to detect the expression of different proteins. The results demonstrated that there was no significant difference of the expression of antioxidantrelated protein HO-1, SOD1 and pro-apoptotic proteins cleaved-caspase 3, cleaved-PARP between MG63 and 

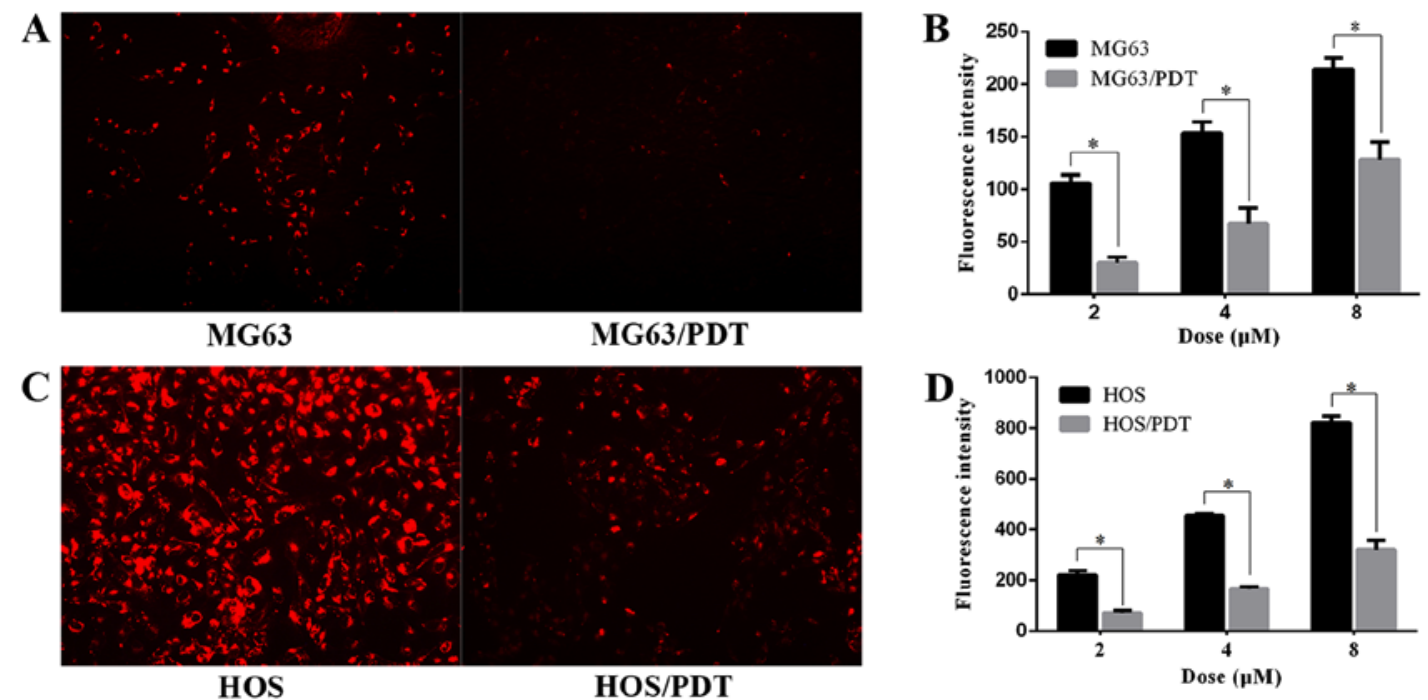

Figure 9. Intracellular MPPa content was analyzed by inverted FM and microplate reader. (A and C) Cells were treated with MPPa (4 $\mu \mathrm{M})$ for 20 h, and then washed using PBS 3 times. The fluorescence intensity representing MPPa content in MG63 and HOS cells was stronger than that in MG63/PDT and HOS/PDT cells. (B and D) Cells were treated with different concentrations of MPPa, 2, 4 and $8 \mu \mathrm{M}$ for $20 \mathrm{~h}$, and subjected to microplate reader ( $\lambda$ exc $525 \mathrm{~nm}$; $\lambda$ em $680 \mathrm{~nm})$. The results indicated that MPPa content in MG63/PDT and HOS/PDT cells was more than that in MG63 and HOS cells, respectively; ${ }^{*} \mathrm{P}<0.05$.
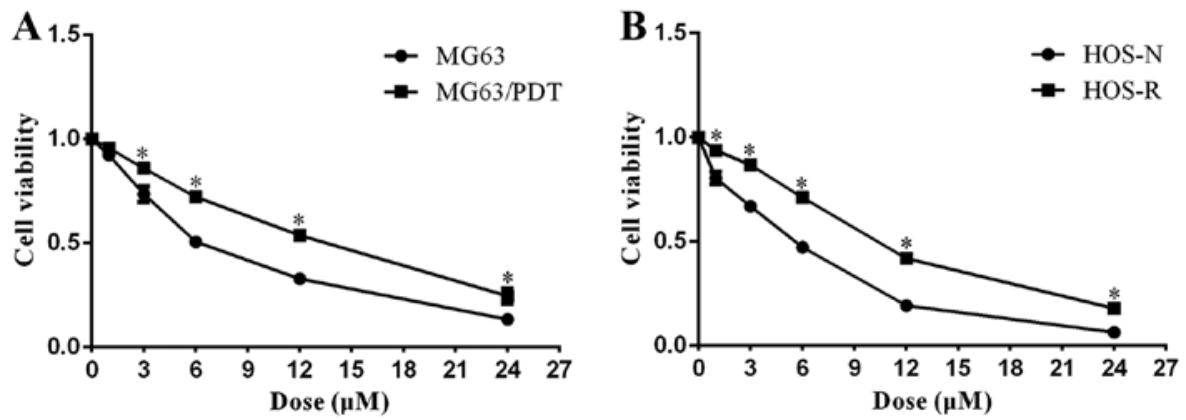

Figure 10. Cell resistance to CDDP. (A) MG63 and MG63/PDT cells were treated with different concentrations of CDDP for 24 h, and then subjected to CCK-8 assay. (B) HOS and HOS/PDT underwent the same treatment. The results indicated that MG63/PDT and HOS-PDT were more resistant to CDDP compared to parental cells MG63 and HOS, respectively; ${ }^{\mathrm{P}}<0.05$.

MG63/PDT cells ( $\mathrm{P}>0.05)$. After treatment with MPPa-PDT for $12 \mathrm{~h}$, the expression of HO-1, SOD1, cleaved-caspase 3 and cleaved-PARP in MG63 and MG63/PDT cells was increased, but their expression in MG63/PDT cells was lower than those in MG63 cells $(\mathrm{P}<0.05$; Fig. $11 \mathrm{~A}$ and $\mathrm{B})$. The expression of HO-1, SOD1, cleaved-caspase 3 and cleaved-PARP in HOS and HOS/PDT cells displayed similar results (Fig. 11C and D).

To further study the characteristics of the resistance and the mechanisms, the expression of drug resistance-related proteins (e.g. ABCG2, MRP1, MDR, apoptosis-related proteins, Bcl-2, Bcl-xL, P-survivin and Bax) and cancer stemness markers CD133 in MG63, MG63/PDT, HOS and HOS/PDT were detected. The results indicated that the levels of ABCG2, MRP1, MDR and the anti-apoptotic proteins Bcl-2, Bcl-xL, P-survivin in MG63/PDT and HOS/PDT cells were all more highly expressed than those in MG63 and HOS cells $(\mathrm{P}<0.05$; Fig. 12). However, the pro-apoptotic protein Bax in MG63/PDT and HOS/PDT cells was significantly downregulated compared with that in their parental cells $(\mathrm{P}<0.05$; Fig. 12). Furthermore, the expression for the cancer stem marker CD133 in MG63/PDT cells and HOS/PDT cells was markedly increased relative to MG63 and HOS cells ( $\mathrm{P}<0.05$; Fig. 12).

\section{Discussion}

The 5-year survival rate of osteosarcoma patients has reached $60-70 \%$ with the continuous improvement of treatment, but the treatment is still not effective for the patients with recurrence, metastasis and chemoresistance. PDT has emerged as an important approach to treat tumors, with some advantages including strong targeting, non-invasive and repeatable treatment (4). Our previous study found that MPPa-mediated photodynamic therapy could significantly kill osteosarcoma MG63 cells, suggesting that it may be used in the clinical treatment of osteosarcoma patients (3). It is well known that resistance is very common in chemotherapy, radiotherapy and other cancer therapy $(21,22)$. This may be related to the existence of heterogeneous cells resistant to the therapy or the induction of resistance in tumor cells (23). Some surviving cells after the treatment become more aggravated, more prone to invasion and metastasis $(13,16)$. However, PDT still encountered the problem of resistance due to the expression of resistance-related proteins.

Milla et al successfully isolated squamous carcinoma cells (SCCs) resistant to PDT by repeated methyl d-aminolevulinic 
A

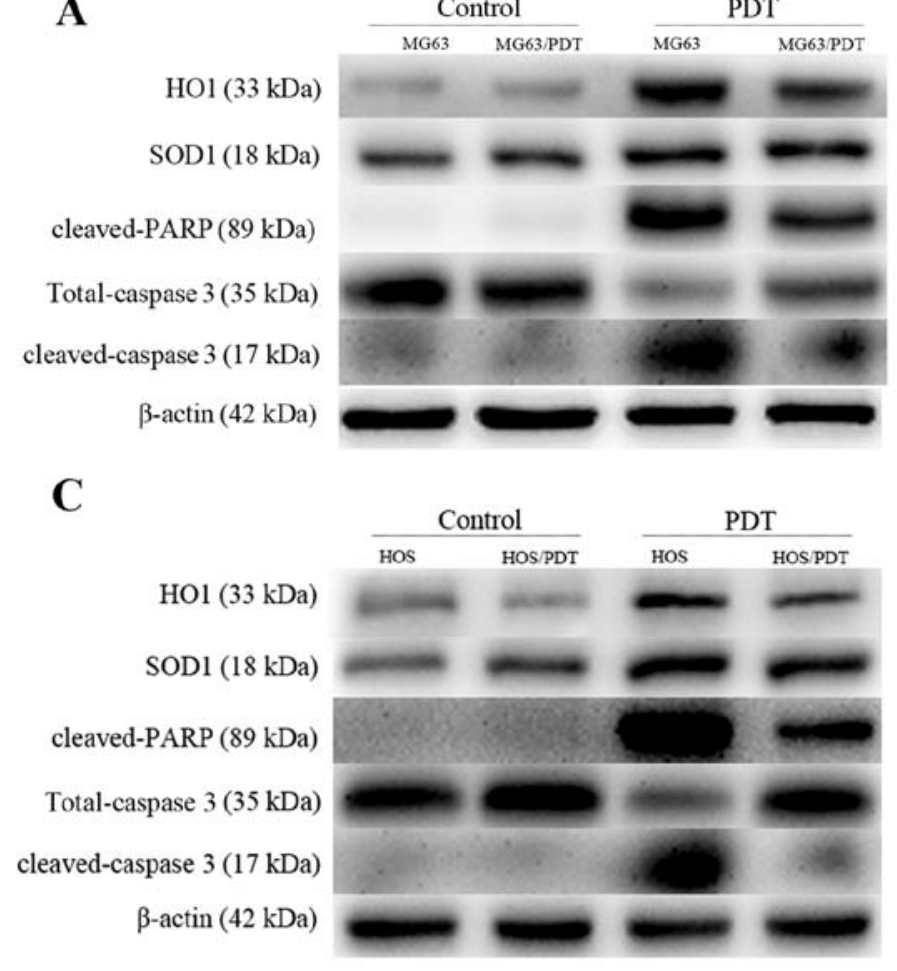

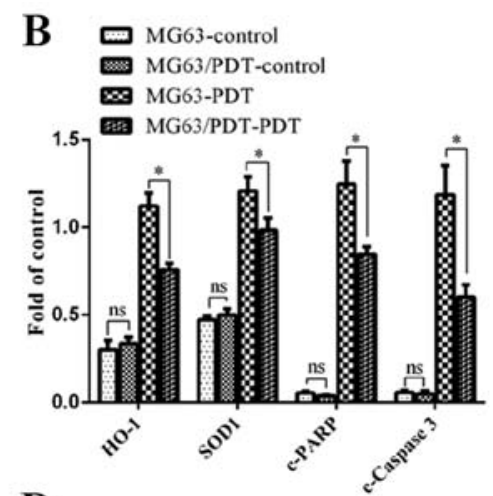

D $\mathrm{D}$ Hos-control

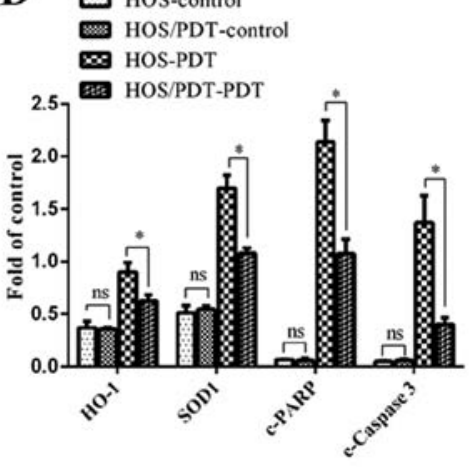

Figure 11. Changes in the expression of antioxidant proteins HO-1, SOD1 and apoptosis proteins cleaved-PARP, total-caspase 3, cleaved-caspase 3 following MPPa-PDT were analyzed by western blotting as depicted in the Materials and methods section. (A and C) WB images of HO-1, SOD1, cleaved-PARP, totalcaspase 3, cleaved-caspase 3 in cells. (B and D) The relative protein expression levels of HO-1, SOD1, cleaved-PARP, cleaved-caspase 3 to $\beta$-actin; " $\mathrm{P}<0.05$; ns $>0.05$.
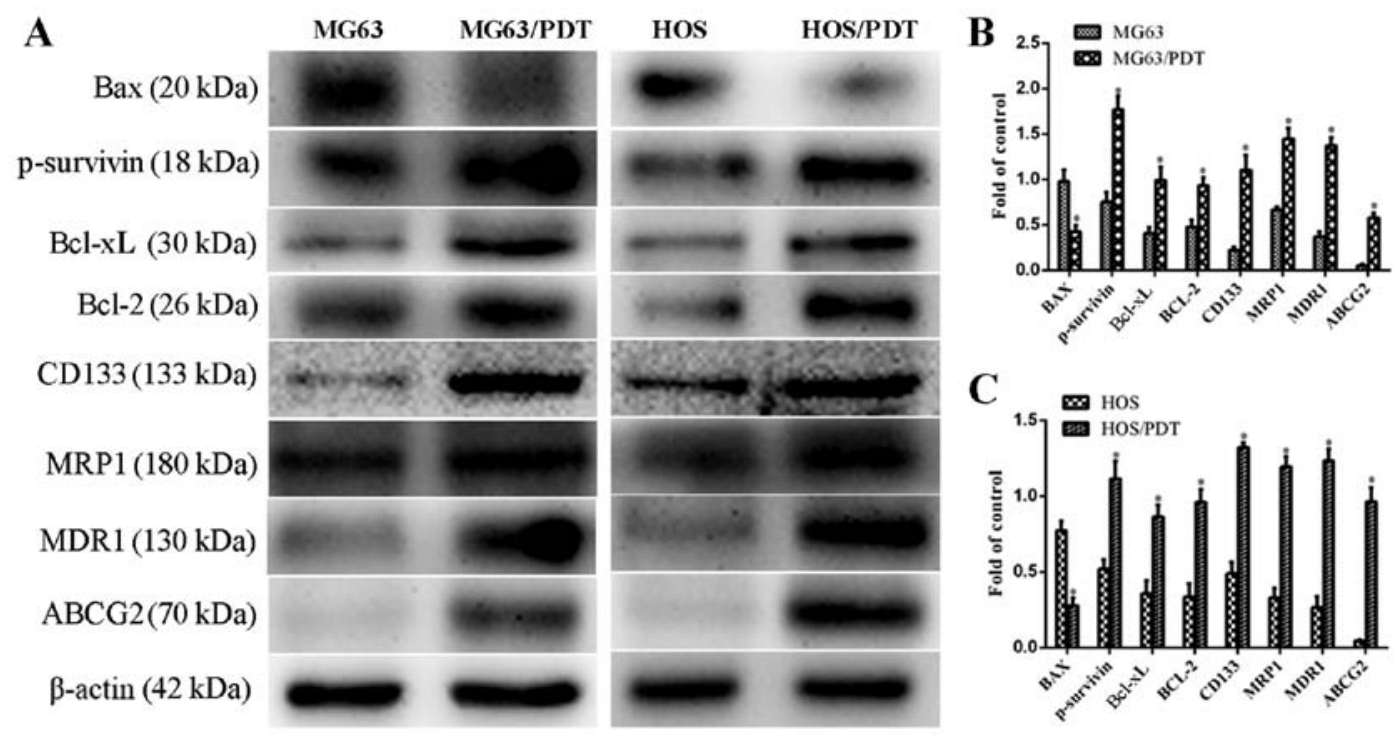

Figure 12. Different expression of Bax, P-survivin, Bcl-xL, Bcl-2, CD133, MRP1, MDR1, ABCG2 between MG63 and MG63/PDT cells and between HOS and HOS/PDT cells. (A) WB images of Bax, P-survivin, Bcl-xL, Bcl-2, CD133, MRP1, MDR1, ABCG2 and $\beta$-actin in MG63, MG63/PDT cells, HOS and HOS/ PDT cells. (B and C) Protein expression levels of Bax, P-survivin, Bcl-xL, Bcl-2, CD133, MRP1, MDR1 and ABCG2 after normalization relative to $\beta$-actin; ${ }^{*} \mathrm{P}<0.05$.

acid (Me-ALA-PDT) treatment of LD90 doses for tumor cells (24). The present study selected LD90 doses of MPPa-PDT for human osteosarcoma cell lines MG63 and HOS to establish new human osteosarcoma cell lines. However, after 3 days of treatment, all the cells died and failed to form resistance. This may be related to mismatch speed of resistance-related molecule expression. Thus, we chose a relatively mild treatment condition of IC40-IC60. The MG63 and HOS cells were subjected to 10 cycles of PDT by gradually increasing the dose of MPPa, and finally MPPa-PDT-resistant cells were obtained, named MG63/PDT and HOS/PDT, respectively. In order to verify the resistance of newly constructed osteosarcoma cell lines MG63/PDT and HOS/PDT to MPPa-PDT, we examined the expression of cleaved-caspase 3 and cleaved-PARP, 
apoptosis, cell viability in MG63, MG63/PDT, HOS and HOS/PDT cells after MPPa-PDT treatment. The results revealed that MG63/PDT and HOS/PDT cells were more resistant to MPPa-PDT compared to their corresponding parental cells. There may be some mechanisms that protected them from the damage of MPPa-PDT in osteosarcoma cells.

ROS is the main mechanism by which PDT kills osteosarcoma cells $(3,25)$. In the present study, ROS in resistant cells MG63/PDT and HOS/PDT and parental cells MG63 and HOS, was analyzed by FCM and FM. The results demonstrated that there was no difference in the ROS level between resistant and parental cells in the absence of treatment. However, after treatment with PDT, the amount of ROS in resistant cells was significantly lower than that in parental cells, suggesting that the resistant cells changed some signal molecules to decrease the production of ROS. The amount of ROS induced by PDT depends on the type and the dose of the photosensitizer, irradiation time and the ability of cells to antioxidative stress. HO-1 not only degrades heme, but also promotes antioxidation, antiinflammation and anti-apoptosis $(26,27)$. Ciesla et al found that upregulation of HO-1 expression in rhabdomyosarcoma could reduce intracellular ROS content and promote cell survival (28). $\mathrm{Lv}$ et al reported that inhibition of HO-1 could increase the sensitivity of laryngeal carcinoma to CDDP. Early studies also found that HO-1 expression could decrease the damage of photodynamic therapy to tumors (29). SOD1 is an important antioxidant enzyme in cells, and is capable of decomposing superoxide, and free cells of ROS damage. Soares et al reported that inhibition of SOD1 increased the sensitivity of tumor cells to photodynamic therapy $(30,31)$. In the present study, HO-1 and SOD1 expression were examined after MPPa-PDT treatment by same MPPa and light dose. However, the results were contrary to our expectation. The expression of HO-1 and SOD1 in resistant cells was significantly lower than those in parental cells, though both of them were induced by MPPa-PDT. In addition, there was no significant difference in the expression of HO-1 and SOD1 between resistant and parental cells without MPPa-PDT treatment. The results indicated that there may be another pathway in resistant cells that induces the resistance to MPPa-PDT. Higher expression of antioxidant machinery of cells definitely should result in low ROS levels in response to a particular treatment. Primitively, we hypothesized that MPPa-PDT-resistant osteosarcoma cells may produce more antioxidant proteins than original cells in order to clean out ROS. However, the results demonstrated that MPPa-PDT-resistant osteosarcoma cells had less antioxidant proteins than original osteosarcoma cells. Tian et al found that the inhibition of antioxidants may increase ROS and the damage of MPPa-PDT on tumor cells (32). There may be another reason for the high expression of antioxidants in parental cells. In one treatment, the expression of antioxidant proteins was adjusted in osteosarcoma cells according to the amount of ROS and formed tolerance to treatment, however this warrants further exploration. Concomitantly, the expression of other anti-oxidative stress kinases in resistant cells was also worthy of further study.

Our previous study revealed that the cytotoxicity of MPPa-PDT on osteosarcoma cells was in a dose-dependent manner (3). Milla et al found that the amount of Me-ALA in resistant SCC was less than that in parental SCC cells after only Me-ALA treatment for $4 \mathrm{~h}$ (24). We hypothesized that certain intracellular content after MPPa treatment resulted in the difference of ROS between resistant and parental cells. By detecting the fluorescence intensity of intracellular MPPa, we found that the content of MPPa in the resistant cells was significantly less than that in parental cells after the identical MPPa treatment, suggesting that the resistant cells could decrease the production of ROS induced by PDT owing to the less content of intracellular photosensitizer compared with that in parental cells. The ABC transporter family proteins with ATP enzyme activity (i.e. ABCG2, MDR1 and MRP1) can diminish intracellular drug concentration by accelerating drug efflux. Ishikawa et al found that inhibition of ABCG2 increased the uptake of photosensitizer PpIX by tumor cells (33). Liu et al reported that inhibition of MDR1 or MRP1 could increase the sensitivity of osteosarcoma cells to chemotherapy $(34,35)$. In the present study, WB results implied that the expression of ABCG2, MDR1 and MRP1 in the resistant cells was significantly unregulated compared to parental cells. The decrease of MPPa content in the tolerant cells may be linked to the high expression of $\mathrm{ABC}$ transporter protein. However, the definite relationship between their high expression and the resistance to MPPa-PDT of MG63/PDT and HOS/PDT cells warrants further studies.

In addition to the upregulation of the $\mathrm{ABC}$ transporter, the anti-apoptotic and pro-apoptotic proteins may also be involved in the formation of cell resistance. The BCL-2 protein family is widely involved in the process of cell apoptosis. The pro-apoptotic protein Bax can increase the permeability of the mitochondrial membrane to facilitate the release of cytochrome $c$ from the mitochondria into the cytoplasm. On the contrary, anti-apoptotic protein Bcl-2 and Bax-xL can stabilize the mitochondrial membrane by inhibiting Bax (20). Previous studies have found that MPPa-PDT can induce apoptosis of osteosarcoma MG63 cells by downregulation of Bcl-2 and the promotion of the expression of Bax (3). Survivin is a member of the inhibitor of apoptosis protein, which can bind caspase 3, an apoptosis executor, thereby inhibiting its activity (19). Ferrario et al found that a reduction of survivin can increase the cytotoxicity of PDT on breast cancer cells (36). The expression of P-survivin is unregulated in PDT-resistant squamous carcinoma cells (24). Our results revealed that the expression of anti-apoptotic protein $\mathrm{Bcl}-2, \mathrm{Bcl}-\mathrm{xL}$ and $\mathrm{P}$-survivin was significantly increased in the resistant cells MG63/PDT and HOS/PDT compared with the parental cells MG63 and HOS, and the expression of pro-apoptotic protein Bax was notably decreased. The results demonstrated that upregulation of anti-apoptotic proteins and downregulation of pro-apoptotic proteins may be one of the mechanisms responsible for PDT-resistance of MG63/PDT and HOS/PDT cells.

Under normal circumstances, the resistant cells may accelerate proliferation to overcome the cytotoxicity of drugs (37). In our experiments, we found that the proliferation ability of the resistant cells MG63/PDT and HOS/PDT was weaker than that of their primary MG63 and HOS cells, respectively. The results are similar to those found in the CDDP resistant osteosarcoma cells SOSP-9607/CDDP (38). The slow proliferation of the resistant cells may be caused by the increased quiescent cells (16). In line with this, our results also demonstrated that there were more cells in the G0/G1 phase in resistant cells MG63/PDT and HOS/PDT compared with their 
corresponding parental cells. PDT can cause DNA damage, which can activate or inhibit some signal molecules to block the cell cycle in the G1 phase and promote DNA repair $(39,40)$. The results revealed that more cells in the G0/G1 phase of the resistant cells MG63/PDT and HOS/PDT could enhance their DNA repair ability, which also may be one of the mechanisms responsible for the PDT-resistance.

Casas et al found that the ability of invasion and migration in PDT-resistant cells was significantly weaker than that of their primary cells (41). However, Milla et al found that the migration ability of PDT-resistant SCC cells was stronger than that of their original cells (24). Han et al found that the invasion ability of CDDP-resistant osteosarcoma cells was also significantly enhanced compared to their primary cells (37). Our results revealed that the invasion, migration and clone formation capacity of resistant cells MG63/PDT and HOS/PDT were also significantly stronger than those of parental cells. The invasion, migration and clone formation may vary depending on the treatment methods, and the type of cells and photosensitizers. The results revealed that the recurrence of osteosarcoma after PDT may become more troublesome.

Cancer stem cells (CSCs) have the capacity of self-renewal and differentiation, and are accountable for proliferation, metastasis, drug resistance and recurrence of tumors (42). CD133 is currently recognized as a tumor stem cell marker, and many researchers have chosen CD133 as a marker for osteosarcoma stem cells to screen osteosarcoma stem cells (43-47). ABCG2 is not only associated with drug resistance, but also as a surface marker of CSC $(48,49)$. It was reported that osteosarcoma-cancer-stem cells exhibited higher expression of ABCG2 and CD133 (50). In the present study, ABCG2 was upregulated in resistant cells. The present study also revealed that MG63/PDT and HOS/PDT cells presented higher expression of CD133 and possessed more $\mathrm{CD}_{133}{ }^{+}$cells compared to their parental cells, demonstrating that the stemness of osteosarcoma cells was enhanced during resistant cell construction by MPPa-PDT, and osteosarcoma stem cells may be involved in PDT-resistance of MG63/PDT and HOS/PDT cells. However, the proportion of CD44 ${ }^{+}$cells, another cancer stem cell maker (51), between parental and resistant cells did not exhibit any significant difference and the slow proliferation and less cells in the G2/M phase of MG63/PDT and HOS/PDT cells were inconsistent with the appearance of cancer stem cells. It has been reported that PDT can conquer the resistance of tumor cells to chemotherapeutic drugs (52). CCK-8 assay was used to detect the viability of the cells treated with different doses of CDDP. The results revealed that the PDT-resistant osteosarcoma cells also appeared to be more resistant to CDDP, suggesting that MG63/PDT and HOS/PDT cells were not only resistant to PDT, but also to chemotherapy.

In conclusion, we successfully constructed two new PDT-resistant osteosarcoma cell lines MG63/PDT and HOS/PDT which featured by strong invasiveness, migration and stemness, and high expression of anti-apoptotic proteins as well as the ABC transporter family proteins, and low expression of pro-apoptotic protein and CDDP tolerance. The newly constructed PDT-resistant cell lines will be beneficial in the exploration of the biological characteristics of recurrent osteosarcoma, the methods of conquering PDT-resistance and to clarify possibly related mechanisms.

\section{Acknowledgements}

The present study was supported by the National Natural Science Foundation of China (81572634), and the Graduate Scientific Innovation Project of Chongqing Education Committee (CYS15141). The authors wish to thank Mr. Yong Zhu, of the Department of Orthopedics, The First Affiliated Hospital of Chongqing Medical University (Chongqing, China), for their advice and supervision with regards to the statistical analysis and modification of the manuscript.

\section{References}

1. Wang W, Yang J, Wang Y, Wang D, Han G, Jia J, Xu M and Bi W: Survival and prognostic factors in Chinese patients with osteosarcoma: 13-year experience in 365 patients treated at a single institution. Pathol Res Pract 213: 119-125, 2017.

2. Whelan J, McTiernan A, Cooper N, Wong YK, Francis M, Vernon S and Strauss SJ: Incidence and survival of malignant bone sarcomas in England 1979-2007. Int J Cancer 131: E508-E517, 2012.

3. Huang Q, Ou YS, Tao Y, Yin H and Tu PH: Apoptosis and autophagy induced by pyropheophorbide- $\alpha$ methyl estermediated photodynamic therapy in human osteosarcoma MG-63 cells. Apoptosis 21: 749-760, 2016

4. Agostinis P, Berg K, Cengel KA, Foster TH, Girotti AW, Gollnick SO, Hahn SM, Hamblin MR, Juzeniene A, Kessel D, et al: Photodynamic therapy of cancer: An update. CA Cancer J Clin 61: 250-281, 2011.

5. Khaled YS, Wright KE, Melcher A and Jayne D: Anti-cancer effects of oncolytic viral therapy combined with photodynamic therapy in human pancreatic cancer cell lines. In: Spring Meeting for Clinician Scientists in Training 2015, 26 Feb, 2015. https://doi.org/10.1016/S0140-6736(15)60371-3.

6. Cheng Y, Chang Y, Feng Y, Liu N, Sun X, Feng Y, Li X and Zhang H: Simulated sunlight-mediated photodynamic therapy for melanoma skin cancer by titanium-dioxide-nanoparticle-goldnanocluster-graphene heterogeneous nanocomposites. Small 13: $1603935,2017$.

7. Kuzyniak W, Schmidt J, Glac W, Berkholz J, Steinemann G, Hoffmann B, Ermilov EA, Gürek AG, Ahsen V, Nitzsche B, et al: Novel zinc phthalocyanine as a promising photosensitizer for photodynamic treatment of esophageal cancer. Int J Oncol 50: 953-963, 2017.

8. Yano T, Kasai H, Horimatsu T, Yoshimura K, Teramukai S, Morita S, Tada H, Yamamoto Y, Kataoka H, Kakushima N, et al: A multicenter phase II study of salvage photodynamic therapy using talaporfin sodium (ME2906) and a diode laser (PNL6405EPG) for local failure after chemoradiotherapy or radiotherapy for esophageal cancer. Oncotarget 8: 22135-22144, 2017.

9. Luo T, Wilson BC and Lu QB: Evaluation of one- and two-photon activated photodynamic therapy with pyropheophorbide-a methyl ester in human cervical, lung and ovarian cancer cells. J Photochem Photobiol B 132: 102-110, 2014.

10. Li KM, Sun X, Koon HK, Leung WN, Fung MC, Wong RN, Lung ML, Chang CK and Mak NK: Apoptosis and expression of cytokines triggered by pyropheophorbide-a methyl estermediated photodynamic therapy in nasopharyngeal carcinoma cells. Photodiagn Photodyn Ther 3: 247-258, 2006.

11. Tian Y, Leung W, Yue K and Mak N: Cell death induced by MPPa-PDT in prostate carcinoma in vitro and in vivo. Biochem Biophys Res Commun 348: 413-420, 2006.

12. Tian YY, Hu XY, Leung WN, Yuan HQ, Zhang LY, Cui FA and Tian X: Investigation of photodynamic effect caused by MPPa-PDT on breast cancer Investigation of photodynamic effect caused by MPPa-PDT. Laser Phys Lett 9: 754-758, 2012.

13. Gilaberte Y, Milla L, Salazar N, Vera-Alvarez J, Kourani O, Damian A, Rivarola V, Roca MJ, Espada J, González S, et al: Cellular intrinsic factors involved in the resistance of squamous cell carcinoma to photodynamic therapy. J Invest Dermatol 134: 2428-2437, 2014 
14. Zamarrón A, Lucena SR, Salazar N, Sanz-Rodríguez F, Jaén P, Gilaberte Y, González S and Juarranz Á: Isolation and characterization of PDT-resistant cancer cells. Photochem Photobiol Sci 14: 1378-1389, 2015.

15. Anderson SJ, Wapnir I, Dignam JJ, Fisher B, Mamounas EP, Jeong JH, Geyer CE Jr, Wickerham DL, Costantino JP and Wolmark N: Prognosis after ipsilateral breast tumor recurrence and locoregional recurrences in patients treated by breast-conserving therapy in five National Surgical Adjuvant Breast and Bowel Project protocols of node-negative breast cancer. J Clin Oncol 27: 2466-2473, 2009.

16. Wang C, Guo LB, Ma JY, Li YM and Liu HM: Establishment and characterization of a paclitaxel-resistant human esophageal carcinoma cell line. Int J Oncol 43: 1607-1617, 2013.

17. Jeon M, Rahman N and Kim YS: Cytoprotective effect of Makgeolli lees on paraquat induced oxidative stress in A549 cells via activation of NRF2 and antioxidant genes. J Microbiol Biotechnol 26: 277-286, 2016.

18. Dean M: ABC transporters, drug resistance, and cancer stem cells. J Mammary Gland Biol Neoplasia 14: 3-9, 2009.

19. Zhang B, Pan JS, Liu JY, Han SP, Hu G and Wang B: Effects of chemotherapy and/or radiotherapy on survivin expression in ovarian cancer. Methods Find Exp Clin Pharmacol 28: 619-625, 2006.

20. Czabotar PE, Lessene G, Strasser A and Adams JM: Control of apoptosis by the BCL-2 protein family: Implications for physiology and therapy. Nat Rev Mol Cell Biol 15: 49-63, 2014.

21. Restifo NP, Smyth MJ and Snyder A: Acquired resistance to immunotherapy and future challenges. Nat Rev Cancer 16 : 121-126, 2016

22. Wicki A, Mandalà M, Massi D, Taverna D, Tang H,Hemmings BA and Xue G: Acquired resistance to clinical cancer therapy: A Twist in physiological signaling. Physiol Rev 96: 805-829, 2016.

23. Solyanik GI: Multifactorial nature of tumor drug resistance. Exp Oncol 32: 181-185, 2010.

24. Milla LN, Cogno IS, Rodríguez ME, Sanz-Rodríguez F, Zamarrón A, Gilaberte Y, Carrasco E, Rivarola VA and Juarranz A: Isolation and characterization of squamous carcinoma cells resistant to photodynamic therapy. J Cell Biochem 112: 2266-2278, 2011.

25. Tu P, Huang Q, Ou Y, Du X, Li K, Tao Y and Yin H: Aloe-emodinmediated photodynamic therapy induces autophagy and apoptosis in human osteosarcoma cell line MG-63 through the ROS/JNK signaling pathway. Oncol Rep 35: 3209-3215, 2016.

26. Chau LY: Heme oxygenase-1: Emerging target of cancer therapy. J Biomed Sci 22: 22, 2015.

27. Furfaro AL, Traverso N, Domenicotti C, Piras S, Moretta L, Marinari UM, Pronzato MA and Nitti M: The Nrf2/HO-1 axis in cancer cell growth and chemoresistance. Oxid Med Cell Longev 2016: 1958174, 2016.

28. Ciesla M, Marona P, Kozakowska M, Jez M, Seczynska M, Loboda A, Bukowska-Strakova K, Szade A, Walawender M Kusior M, et al: Heme oxygenase-1 controls an HDAC4-miR-206 pathway of oxidative stress in rhabdomyosarcoma. Cancer Res 76: 5707-5718, 2016.

29. Lv X, Song DM, Niu YH and Wang BS: Inhibition of heme oxygenase-1 enhances the chemosensitivity of laryngeal squamous cell cancer Hep-2 cells to cisplatin. Apoptosis 21 : 489-501, 2016.

30. Soares HT, Campos JR, Gomes-da-Silva LC, Schaberle FA, Dabrowski JM and Arnaut LG: Pro-oxidant and antioxidant effects in Photodynamic Therapy: Cells recognize that not all exogenous ROS are alike. ChemBioChem 17: 836-842, 2016.

31. Wright KE, MacRobert AJ and Phillips JB: Inhibition of specific cellular antioxidant pathways increases the sensitivity of neurons to meta-tetrahydroxyphenyl chlorin-mediated photodynamic therapy in a 3D co-culture model. Photochem Photobiol 88 $1539-1545,2012$

32. Tian S, Yong M, Zhu J, Zhang L, Pan L, Chen Q, Li KT, Kong YH, Jiang Y, Yu TH, et al: Enhancement of the effect of methyl pyropheophorbide-a-mediated photodynamic therapy was achieved by increasing ROS via inhibition of Nrf2-HO-1 or Nrf2ABCG2 signaling. Anticancer Agents Med Chem 17: 1, 2017.
33. Ishikawa $T$, Nakagawa $H$, Hagiya $Y$, Nonoguchi $N$, Miyatake $S$ and Kuroiwa T: Key role of human ABC transporter ABCG2 in photodynamic therapy and photodynamic diagnosis. Adv Pharmacol Sci 2010: 587306, 2010.

34. Li C, Guo D, Tang B, Zhang Y, Zhang K and Nie L: Notch1 is associated with the multidrug resistance of hypoxic osteosarcoma by regulating MRP1 gene expression. Neoplasma 63: 734-742, 2016.

35. Liu T, Li Z, Zhang Q, De Amorim Bernstein K, LozanoCalderon S, Choy E, Hornicek FJ and Duan Z: Targeting $A B C B 1$ $(M D R 1)$ in multi-drug resistant osteosarcoma cells using the CRISPR-Cas9 system to reverse drug resistance. Oncotarget 7: 83502-83513, 2016.

36. Ferrario A, Rucker N, Wong S, Luna M and Gomer CJ: Survivin, a member of the inhibitor of apoptosis family, is induced by photodynamic therapy and is a target for improving treatment response. Cancer Res 67: 4989-4995, 2007.

37. Otto T and Sicinski P: Cell cycle proteins as promising targets in cancer therapy. Nat Rev Cancer 17: 93-115, 2017.

38. Han T, Zhu X, Wang J, Zhao H, Ma Q, Zhao J, Qiu X and Fan Q: Establishment and characterization of a cisplatin-resistant human osteosarcoma cell line. Oncol Rep 32: 1133-1139, 2014.

39. Baldea I, Olteanu DE, Bolfa P, Tabaran F, Ion RM and Filip GA: Melanogenesis and DNA damage following photodynamic therapy in melanoma with two meso-substituted porphyrins. J Photochem Photobiol B 161: 402-410, 2016.

40. Borgstahl GEO, Brader K, Mosel A, Liu S, Kremmer E, Goettsch KA, Kolar C, Nasheuer HP and Oakley GG: Interplay of DNA damage and cell cycle signaling at the level of human replication protein A. DNA Repair 21: 12-23, 2014.

41. Casas A, Di Venosa G, Vanzulli S, Perotti C, Mamome L, Rodriguez L, Simian M, Juarranz A, Pontiggia O, Hasan T, et al: Decreased metastatic phenotype in cells resistant to aminolevulinic acid-photodynamic therapy. Cancer Lett 271: 342-351, 2008.

42. Stuckey DW and Shah K: Stem cell-based therapies for cancer treatment: Separating hope from hype. Nat Rev Cancer 14: 683-691, 2014.

43. Tirino V, Desiderio V, d'Aquino R, De Francesco F, Pirozzi G, Graziano A, Galderisi U, Cavaliere C, De Rosa A, Papaccio G, et al: Detection and characterization of $\mathrm{CD} 133^{+}$cancer stem cells in human solid tumours. PLoS One 3: e3469, 2008.

44. Veselska R, Hermanova M, Loja T, Chlapek P,Zambo I, Vesely K, Zitterbart K and Sterba J: Nestin expression in osteosarcomas and derivation of nestin/CD133 positive osteosarcoma cell lines. BMC Cancer 8: 300, 2008.

45. He A, Qi W, Huang Y, Feng T, Chen J, Sun Y, Shen Z and Yao Y: CD133 expression predicts lung metastasis and poor prognosis in osteosarcoma patients: A clinical and experimental study. Exp Ther Med 4: 435-441, 2012

46. Li J, Zhong XY, Li ZY, Cai JF, Zou L, Li JM, Yang T and Liu W: CD133 expression in osteosarcoma and derivation of CD133 ${ }^{+}$ cells. Mol Med Rep 7: 577-584, 2013.

47. Ricci-Vitiani L, Lombardi DG, Pilozzi E, Biffoni M, Todaro M, Peschle C and De Maria R: Identification and expansion of human colon-cancer-initiating cells. Nature 445: 111-115, 2007.

48. Robey RW, Polgar O, Deeken J, To KW and Bates SE: ABCG2: Determining its relevance in clinical drug resistance. Cancer Metastasis Rev 26: 39-57, 2007.

49. Ding XW, Wu JH and Jiang CP: ABCG2: A potential marker of stem cells and novel target in stem cell and cancer therapy. Life Sci 86: 631-637, 2010.

50. Di Fiore R, Santulli A, Ferrante RD, Giuliano M, De Blasio A, Messina C, Pirozzi G, Tirino V, Tesoriere G and Vento R: Identification and expansion of human osteosarcoma-cancerstem cells by long-term 3 -aminobenzamide treatment. J Cell Physiol 219: 301-313, 2009.

51. Jaggupilli A and Elkord E: Significance of CD44 and CD24 as cancer stem cell markers: An enduring ambiguity. Clin Dev Immunol 2012: 708036, 2012.

52. Spring BQ, Rizvi I, Xu N and Hasan T: The role of photodynamic therapy in overcoming cancer drug resistance. Photochem Photobiol Sci 14: 1476-1491, 2015. 